\title{
Response Surface Methodology for the Optimization of Preparation of Biocomposites Based on Poly(lactic acid) and Durian Peel Cellulose
}

\author{
Patpen Penjumras, ${ }^{1,2}$ Russly Abdul Rahman, ${ }^{1,3}$ Rosnita A. Talib, ${ }^{1}$ and Khalina Abdan ${ }^{4}$ \\ ${ }^{1}$ Department of Process and Food Engineering, Faculty of Engineering, Universiti Putra Malaysia (UPM), \\ 43400 Serdang, Selangor, Malaysia \\ ${ }^{2}$ Department of Food Science and Technology, Maejo University, Phrae Campus, Phrae 54140, Thailand \\ ${ }^{3}$ Department of Food Technology, Faculty of Food Science and Technology, Universiti Putra Malaysia (UPM), \\ 43400 Serdang, Selangor, Malaysia \\ ${ }^{4}$ Department of Biological and Agricultural Engineering, Faculty of Engineering, Universiti Putra Malaysia (UPM), \\ 43400 Serdang, Selangor, Malaysia
}

Correspondence should be addressed to Patpen Penjumras; p_atp@hotmail.com and Russly Abdul Rahman; russly@upm.edu.my

Received 8 April 2015; Accepted 2 June 2015

Academic Editor: Runcang Sun

Copyright (C) 2015 Patpen Penjumras et al. This is an open access article distributed under the Creative Commons Attribution License, which permits unrestricted use, distribution, and reproduction in any medium, provided the original work is properly cited.

\begin{abstract}
Response surface methodology was used to optimize preparation of biocomposites based on poly(lactic acid) and durian peel cellulose. The effects of cellulose loading, mixing temperature, and mixing time on tensile strength and impact strength were investigated. A central composite design was employed to determine the optimum preparation condition of the biocomposites to obtain the highest tensile strength and impact strength. A second-order polynomial model was developed for predicting the tensile strength and impact strength based on the composite design. It was found that composites were best fit by a quadratic regression model with high coefficient of determination $\left(R^{2}\right)$ value. The selected optimum condition was 35 wt.\% cellulose loading at $165^{\circ} \mathrm{C}$ and $15 \mathrm{~min}$ of mixing, leading to a desirability of $94.6 \%$. Under the optimum condition, the tensile strength and impact strength of the biocomposites were $46.207 \mathrm{MPa}$ and $2.931 \mathrm{~kJ} / \mathrm{m}^{2}$, respectively.
\end{abstract}

\section{Introduction}

The agricultural and agrofood industries produce great amounts of wastes, which exhibit a tremendous threat to the environment [1]. These agricultural wastes and by-products cause negative impacts in terms of environmental concern due to the increasing amount of pollutant disposal and in terms of industrial sustainability due to the high costs related to their management [2]. Recovering, recycling, and converting of by-products and wastes into value-added products are the policy to control the stream of organic wastes [3]. Therefore, the development of bio-based material has been studied by many researchers. In recent years, the use of natural plant fibers as a reinforcement material in fiberreinforced plastics (FRP) has been gaining attention due to its advantages such as renewability, low density, and high specific strength $[4,5]$. Several plants, such as kenaf, cotton, wood, bamboo, flax, hemp, sisal, jute, and ramie, are rich in cellulose and have been used to reinforce polymers to produce biocomposite materials [6-9]. In the last decade, however, research focusing on the use of cellulosic waste as filler has grown rapidly. Agrowaste materials such as banana rachis, mulberry bark, soybean, soy hulls [10], wheat straw $[10,11]$, pineapple leaf fiber [12], barley husk and coconut shell [13], rice husk [14], and sugarcane bagasse [15] have been studied as a resource in the production of cellulose fiber.

Cellulose is an important structural component of all plant materials which confers strength and stability to the plant cell walls [16] and is constantly replenished by photosynthesis $[17,18]$. It is organized into microfibrils in 
the cell wall, interrupted by hemicellulose and surrounded by a lignin matrix. Alkali treatment or mercerization is normally used for preparation of cellulose [19]. The alkali treatment is a process of subjecting natural fibers in an interaction with a strong basic aqueous solution to remove noncellulosic components as waxy materials, lignin, hemicellulose, and impurities [20]. The fiber cell walls swell and become round, thus increasing the strength [19].

Using nano- and microcellulose as reinforcements for epoxy or phenol-formaldehyde resins, polymethylmethacrylate, polypropylene, polystyrene, and styrene copolymers has been extensively studied in the past years [21]. The major advantage of cellulose is that it is a good source of biodegradable material. The biodegradability of blends of thermoplastics, low density polyethylene (LDPE), and high density polyethylene (HDPE) with kenaf cellulose has been studied, showing that cellulose content greater than $30 \mathrm{wt} . \%$ led to higher degradation [22]. Generally, commodity plastics are widely used for many applications such as packaging material; however, the plastic materials take very long time for environment decomposition, which represent a serious problem with disposal of plastic waste. Substituting nonbiodegradable polymers with biodegradable ones leads to fully renewable and degradable composites [21]. Among the many biodegradable polymers, poly(lactic acid) (PLA) is considered to be one of the most promising renewable resourcebased biopolymer matrices due to its high mechanical properties and easy processability compared to other biopolymers [23]. Moreover, its packaging performance characteristics are closely similar to those of polyethylene terephthalate (PET) [24]. Various studies of PLA reinforced with natural fiber have been reported $[4,21,25-33]$. Although a variety of natural fibers were investigated in detail, the use of durian rind cellulose as reinforcing material in PLA has not yet been explored.

Durian (Durio zibethinus Murray) is the most popular fruit in Southeast Asia [34]. The consumption of durian and its products has been phenomenal in the global trade market. The total world harvest of durian is $1.4 \mathrm{Mt}$, dominated by major producers: Thailand (781 kt), Malaysia $(376 \mathrm{kt})$, and Indonesia (265 kt) [35]. It has been vigorously expanded and entrenched into a multidisciplinary of food processing industries, but only one-third of durian is edible, whereas the seeds and the shell become wastes which generate a large amount of biological waste [34]. In common practice, durian residues are burned or sent to landfills, without regard to the surrounding environment [35]. Suitable methods have to be adopted to utilize the waste for the conversion into upgraded products. Durian rind was found to have a good source of cellulose [36]. In our previous paper [37], we reported that the cellulose obtained from durian peel was $33.12 \pm 0.108 \%$ which is similar with wheat and barley that consist of cellulose approximately $28-48,29-51$, and $31-45 \%$, respectively, and $26-43 \%$ in bamboo cane fiber [38]. Therefore, the use of cellulose from durian rind as the reinforcing material in PLA was investigated in this study.

The effects of input variables (cellulose loading, mixing temperature, and mixing time) on the mechanical properties (tensile strength and impact strength) were studied on surface plots and contour plots. In addition, the optimized conditions of the independent variables to maximize tensile strength and impact strength of composites were also reported in this research.

\section{Experimental}

2.1. Materials. Poly(lactic acid) (PLA) (Ingeo biopolymer 2003D food packaging-grade with melting flow index of $6 \mathrm{~g} / 10 \mathrm{~min}$ at $210^{\circ} \mathrm{C}$; specific gravity of $1.24 ;>98 \%$ purity) was purchased in pellets from Natureworks (USA). Durian peel was collected from Phatthalung Province, Thailand. Reagent-grade sodium hydroxide $(\mathrm{NaOH})$ and acetic acid $\left(\mathrm{CH}_{3} \mathrm{COOH}\right)$ and technical-grade sodium chlorite $\left(\mathrm{NaClO}_{2}\right)$ of $80 \%$ purity were purchased from Fisher Chemicals Sdn. Bhd. (Malaysia).

2.2. Extraction of Cellulose from Durian Peel. The durian peel was first sun-dried and was then ground as in Figures 1(a) and 1(b). Delignification and mercerization were used to extract cellulose according to Tawakkal et al. [30] with slight modifications. Firstly, delignification was used to produce holocellulose; $20 \mathrm{~g}$ of sample was rinsed with tap water to remove dust and was subsequently soaked in a $1,000 \mathrm{~mL}$ beaker with $640 \mathrm{~mL}$ of distilled water. The beaker was then transferred to a $70^{\circ} \mathrm{C}$ water bath. Next, $4 \mathrm{~mL}$ of $\mathrm{CH}_{3} \mathrm{COOH}$ and $8 \mathrm{~g}$ of $\mathrm{NaClO}_{2}$ were added to the beaker. Every subsequent hour for total of $5 \mathrm{~h}$, the same amount of $\mathrm{CH}_{3} \mathrm{COOH}$ and $\mathrm{NaClO}_{2}$ was added in which lignin was completely separated from the sample. The delignification process was indicated by the color change of samples from brown to white. After that, the sample was left in the water bath overnight. Finally, holocellulose was then filtered, washed, and rinsed with tap water until the yellow color with an odor of chlorine dioxide was removed and the wash water was clear. Secondly, holocellulose was converted to cellulose by mercerization or alkali treatment at room temperature. The holocellulose was added with $80 \mathrm{~mL}$ of $17.5 \% \mathrm{w} / \mathrm{v} \mathrm{NaOH}$ and the mixture was stirred with a glass rod. Another $40 \mathrm{~mL}$ of $17.5 \%$ w/v $\mathrm{NaOH}$ was added to the mixture every $5 \mathrm{~min}$, three times. The mixture was allowed to sit for $30 \mathrm{~min}$, making the total duration $45 \mathrm{~min}$. Then, $240 \mathrm{~mL}$ of distilled water was added to the mixture and allowed to stand for $1 \mathrm{~h}$ before filtering. Next, $800 \mathrm{~mL}$ of $8.3 \% \mathrm{w} / \mathrm{v} \mathrm{NaOH}$ was added to the cellulose for $5 \mathrm{~min}$ followed by rinsing with water. The alkaline cellulose was then neutralized by adding $120 \mathrm{~mL}$ of $10 \%$ v/v acetic acid. The cellulose was subjected to acid treatment for $5 \mathrm{~min}$. Finally, the cellulose was filtered, washed, and rinsed with distilled water until the cellulose residue was free from acid and then dried overnight in a vacuum oven at $80^{\circ} \mathrm{C}$. The cellulose obtained is shown as in Figure 1(c). The cellulose was kept in an air tight container at room temperature until analysis.

2.3. Characterization of Morphological Feature. The SEM [S$3400 \mathrm{~N}$, Hitachi, Japan] images were taken to elucidate the morphologies of the untreated durian peel and cellulose. 


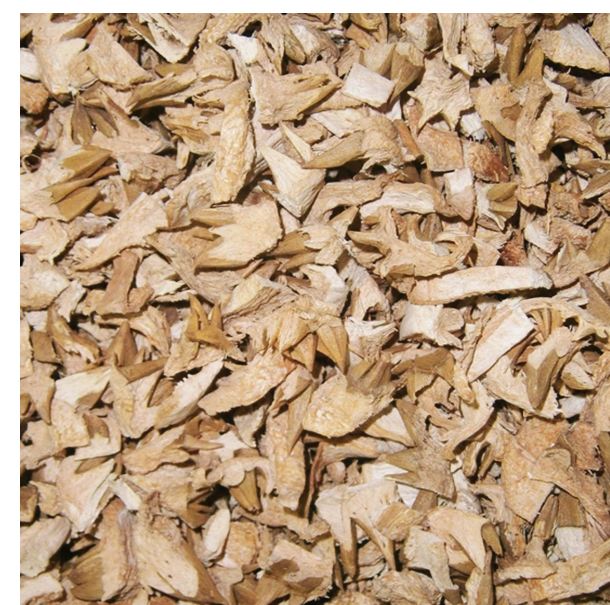

(a)

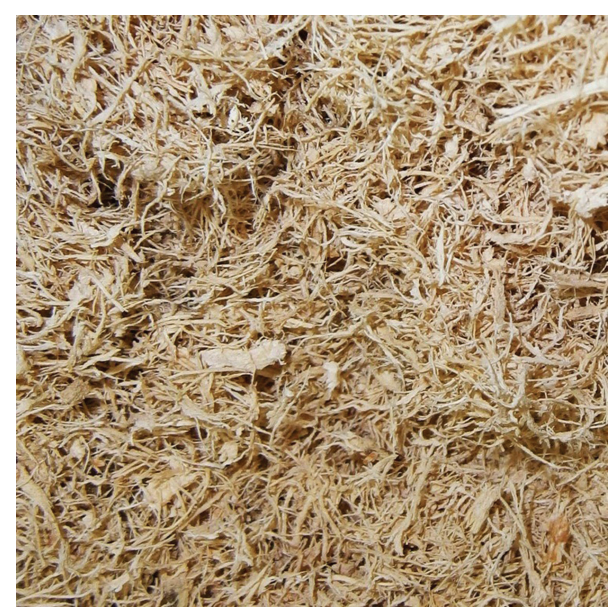

(b)

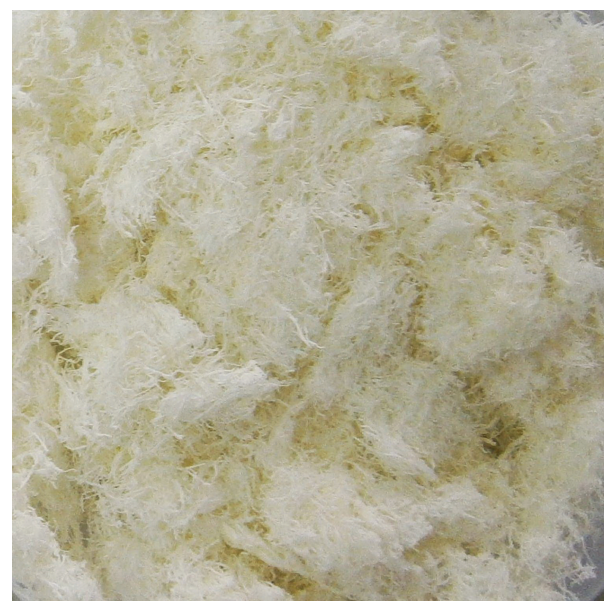

(c)

FIGURE 1: Macroscopic image of (a) durian peel, (b) ground durian peel, and (c) cellulose.

Samples were mounted on aluminum studs and coated with gold in a vacuum before being observed using a SEM.

2.4. Preparation of Biocomposites. The cellulose was ground using grinder and then passed through a sieve (Retsch, AS 200 digit, Germany). The cellulose of sizes 250 to $125 \mu \mathrm{m}$ was collected. The PLA and cellulose were mixed using an internal mixer (Brabender Plastograph EC, Germany) at a $50 \mathrm{rpm}$ screw speed. Various biocomposites were created at different cellulose loadings, mixing temperatures, and mixing times. To prevent pores' formation, the biocomposites were dried in a convection oven at $80^{\circ} \mathrm{C}$ for $16 \mathrm{~h}$ before further processing. The test specimens were then transferred into a rectangular mould with dimensions of $150 \mathrm{~mm} \times$ $150 \mathrm{~mm}$. Moulded biocomposites sheets were produced using a hot press machine at $160^{\circ} \mathrm{C}$. This process involved $5 \mathrm{~min}$ of preheating and $5 \mathrm{~min}$ of pressing, followed by $2 \mathrm{~min}$ of cooling for tensile testing specimens with $1 \mathrm{~mm}$ thickness. Eight minutes of preheating, $7 \mathrm{~min}$ of pressing, and $3 \mathrm{~min}$ of cooling were used to produce samples for impact testing with $3 \mathrm{~mm}$ thicknesses. All biocomposites were packaged in air tight containers and stored at room temperature until analysis.

2.5. Mechanical Testing. The tensile strengths were determined using an Instron Universal Testing Machine (Model 5566; USA) at a cross speed of $5 \mathrm{~mm} / \mathrm{min}$ on specimens with dimensions of $12.7 \mathrm{~mm} \times 63 \mathrm{~mm} \times 1 \mathrm{~mm}$ according to ASTM 1882L [39], until tensile failure was detected. Five samples of each biocomposites were tested. The impact test was performed using an Impact Pendulum Tester (Ceast Model 9050) on $2.5 \mathrm{~mm}$ notched rectangular specimens with dimensions of $12.7 \mathrm{~mm} \times 63 \mathrm{~mm} \times 3 \mathrm{~mm}$ according to ASTM D256 [40]. The Izod method was conducted with a $0.5 \mathrm{~J}$ hammer. Seven samples of each biocomposites were tested.

2.6. Experimental Design and Statistical Analysis. Response surface methodology (RSM) was used to optimize the conditions for thepreparation of composites. The design of experiment was done using Design Expert 9 (Stat-Ease Inc, USA). Three independent variables were employed by central composite design (CCD). The variables used were cellulose 


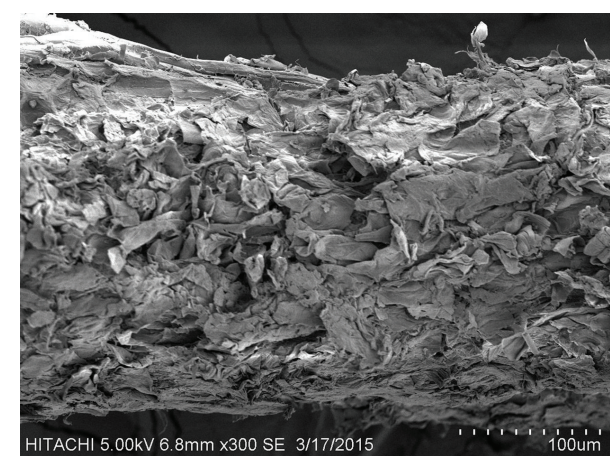

(a)

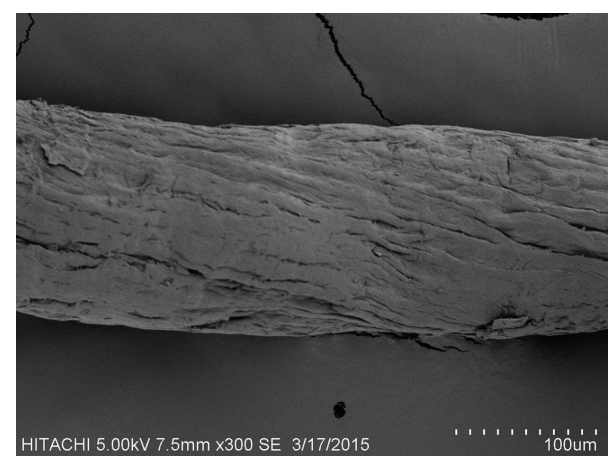

(b)

FIGURE 2: Scanning electron micrograph of (a) untreated durian peel and (b) cellulose.

TABLE 1: Coded levels of variables.

\begin{tabular}{lccccc}
\hline \multirow{2}{*}{ Variables } & \multicolumn{5}{c}{ Coded levels } \\
& $-\alpha$ & -1 & $0^{\text {a }}$ & +1 & $+\alpha$ \\
\hline$X_{1}$ : cellulose loading (wt. \%) & 21.6 & 25 & 30 & 35 & 38.4 \\
$X_{2}$ : temperature $\left({ }^{\circ} \mathrm{C}\right)$ & 161.6 & 165 & 170 & 175 & 178.4 \\
$X_{3}$ : time (min) & 11.6 & 15 & 20 & 25 & 28.4 \\
\hline
\end{tabular}

${ }^{\mathrm{a}}$ Center point; $k=3$ (three independent variables). $\alpha=1.6818$.

loading $\left(X_{1}\right)$, mixing temperature $\left(X_{2}\right)$, and mixing time $\left(X_{3}\right)$. The design consisted of 20 runs including six axial experiments (levels $\pm \alpha$ ), eight factorial experiments (levels \pm 1 ), and six replicates in center point. The level of factors and their coding are presented in Table 1. The design matrix is presented in Table 2. The response functions measured were tensile strength and impact strength. A second-order polynomial equation, as a function of $X$, was fitted for each factor as follows:

$$
Y=\beta_{0}+\sum_{i=1}^{3} \beta_{i} X_{i}+\sum_{i=1}^{3} \beta_{i i} X_{i}^{2}+\sum_{\substack{i=1 \\ i<j}}^{3} \beta_{i j} X_{i} X_{j},
$$

where $Y$ is the estimated response; $\beta_{0}, \beta_{i}, \beta_{i i}$, and $\beta_{i j}$ are constant coefficients ( $\beta_{0}$ a constant, $\beta_{i}$ the coefficients for linear terms, $\beta_{i i}$ the coefficients for quadratic terms, and $\beta_{i j}$ the coefficients for interactive terms); and $X_{1}, X_{2}$, and $X_{3}$ are the coded values of the independent variables of cellulose loading (wt.\%), mixing temperature $\left({ }^{\circ} \mathrm{C}\right)$, and mixing time $(\mathrm{min})$, respectively. The variance for each factor was partitioned into linear, quadratic, and interactive terms. The lack-of-fit and error components were used in determining the significance of these variables and the suitability of the second-order polynomial function.

2.7. Fourier Transform Infrared Spectroscopy (FTIR). The change in chemical compositions of untreated durian peel, cellulose, and optimal biocomposites was examined by FTIR (Perkin Elmer, Spectrum One FT-IR Spectrometer, USA). All the spectra were recorded in the transmittance mode with
TABLE 2: The arrangement of the central composite design.

\begin{tabular}{lcccccc}
\hline \multirow{3}{*}{ Trial } & \multicolumn{3}{c}{ Coded variables } & \multicolumn{3}{c}{ Actual variables } \\
& $X_{1}$ & $X_{2}$ & $X_{3}$ & $X_{1}(\%)$ & $X_{2}\left({ }^{\circ} \mathrm{C}\right)$ & $X_{3}(\mathrm{~min})$ \\
\hline 1 & -1 & -1 & -1 & 25 & 165 & 15 \\
2 & -1 & -1 & +1 & 25 & 165 & 25 \\
3 & -1 & +1 & -1 & 25 & 175 & 15 \\
4 & -1 & +1 & +1 & 25 & 175 & 25 \\
5 & +1 & -1 & -1 & 35 & 165 & 15 \\
6 & +1 & -1 & +1 & 35 & 165 & 25 \\
7 & +1 & +1 & -1 & 35 & 175 & 15 \\
8 & +1 & +1 & +1 & 35 & 175 & 25 \\
9 & $-\alpha$ & 0 & 0 & 21.6 & 170 & 20 \\
10 & $+\alpha$ & 0 & 0 & 38.4 & 170 & 20 \\
11 & 0 & $-\alpha$ & 0 & 30 & 161.6 & 20 \\
12 & 0 & $+\alpha$ & 0 & 30 & 178.4 & 20 \\
13 & 0 & 0 & $-\alpha$ & 30 & 170 & 11.6 \\
14 & 0 & 0 & $+\alpha$ & 30 & 170 & 28.4 \\
15 & 0 & 0 & 0 & 30 & 170 & 20 \\
16 & 0 & 0 & 0 & 30 & 170 & 20 \\
17 & 0 & 0 & 0 & 30 & 170 & 20 \\
18 & 0 & 0 & 0 & 30 & 170 & 20 \\
19 & 0 & 0 & 0 & 30 & 170 & 20 \\
20 & 0 & 0 & 0 & 30 & 170 & 20 \\
\hline & & & & & &
\end{tabular}

a resolution of $4 \mathrm{~cm}^{-1}$ in the range of 4000 to $650 \mathrm{~cm}^{-1}$. Ten scans were averaged for each sample.

\section{Results and Discussion}

3.1. Morphology Analysis. Figure 2 compares the micrographs of untreated durian peel and cellulose. The micrograph of untreated durian peel shows the amount of noncellulosic components; pectin, lignin, and hemicellulose scattered over the surface [18], which provide the bigger diameter than cellulose. These components were then removed after delignification and alkali treatment. The important consequence of diameter reduction was higher reinforcing ability of the cellulose for composite application because the increasing 
TABLE 3: The responses of the parameters used in central composite design.

\begin{tabular}{|c|c|c|c|c|c|}
\hline \multirow{2}{*}{ Trial } & \multicolumn{3}{|c|}{ Independent variables } & \multicolumn{2}{|c|}{ Responses } \\
\hline & Cellulose loading (\%) & Temperature $\left({ }^{\circ} \mathrm{C}\right)$ & Time (min) & Tensile strength $(\mathrm{MPa})$ & Impact strength $\left(\mathrm{kJ} / \mathrm{m}^{2}\right)$ \\
\hline 1 & 25 & 165 & 15 & $40.735 \pm 1.184$ & $2.519 \pm 0.510$ \\
\hline 2 & 25 & 165 & 25 & $33.318 \pm 0.817$ & $2.010 \pm 0.122$ \\
\hline 3 & 25 & 175 & 15 & $39.762 \pm 1.092$ & $2.290 \pm 0.310$ \\
\hline 4 & 25 & 175 & 25 & $28.707 \pm 1.231$ & $2.025 \pm 0.248$ \\
\hline 5 & 35 & 165 & 15 & $48.010 \pm 1.208$ & $2.876 \pm 0.356$ \\
\hline 6 & 35 & 165 & 25 & $47.556 \pm 1.669$ & $2.851 \pm 0.227$ \\
\hline 7 & 35 & 175 & 15 & $40.174 \pm 0.663$ & $2.445 \pm 0.131$ \\
\hline 8 & 35 & 175 & 25 & $36.800 \pm 1.380$ & $2.019 \pm 0.538$ \\
\hline 9 & 21.6 & 170 & 20 & $33.615 \pm 1.461$ & $1.922 \pm 0.171$ \\
\hline 10 & 38.4 & 170 & 20 & $46.114 \pm 0.956$ & $2.944 \pm 0.341$ \\
\hline 11 & 30 & 161.6 & 20 & $41.067 \pm 1.901$ & $2.464 \pm 0.297$ \\
\hline 12 & 30 & 178.4 & 20 & $31.662 \pm 1.146$ & $2.241 \pm 0.540$ \\
\hline 13 & 30 & 170 & 11.6 & $35.793 \pm 1.076$ & $2.493 \pm 0.196$ \\
\hline 14 & 30 & 170 & 28.4 & $31.984 \pm 1.048$ & $2.250 \pm 0.289$ \\
\hline 15 & 30 & 170 & 20 & $29.920 \pm 2.051$ & $2.053 \pm 0.210$ \\
\hline 16 & 30 & 170 & 20 & $30.658 \pm 1.483$ & $1.952 \pm 0.252$ \\
\hline 17 & 30 & 170 & 20 & $31.150 \pm 1.286$ & $1.930 \pm 0.250$ \\
\hline 18 & 30 & 170 & 20 & $30.549 \pm 0.845$ & $1.993 \pm 0.165$ \\
\hline 19 & 30 & 170 & 20 & $29.666 \pm 1.615$ & $2.028 \pm 0.153$ \\
\hline 20 & 30 & 170 & 20 & $31.192 \pm 1.501$ & $2.094 \pm 0.203$ \\
\hline
\end{tabular}

of aspect ratio ( $L / d, L$ is the length and $d$ is diameter) [10]. Generally, the minimum aspect ratio for good strength transmission for any reinforcement material is considered at 10 [41]. In our previous paper [37], diameter distribution and aspect ratio of 70 samples of cellulose were investigated and found that the most cellulose presented diameter and aspect ratio in the range of $100-150 \mu \mathrm{m}$ and $20-25$, respectively. Thus cellulose from durian peel had an aspect ratio superior to this value.

3.2. Tensile Strength and Impact Strength. The results of the 20 runs to determine the tensile strength and impact strength of composites using the internal mixer are tabulated in Table 3. The three factors tested in this study were cellulose loading, mixing temperature, and mixing time. The tensile strength of the composites ranged from 28.707 to $48.010 \mathrm{MPa}$ and impact strength ranged from 1.922 to $2.944 \mathrm{~kJ} / \mathrm{m}^{2}$. The highest tensile strength value was $48.010 \mathrm{MPa}$ under test conditions of $35 \mathrm{wt}$ \% cellulose loading, $165^{\circ} \mathrm{C}$, and $15 \mathrm{~min}$ of mixing. The highest impact strength value was $2.944 \mathrm{~kJ} / \mathrm{m}^{2}$ at $38.4 \mathrm{wt}$ \% cellulose loading, $170^{\circ} \mathrm{C}$, and $20 \mathrm{~min}$ of mixing; meanwhile, the lowest tensile strength value was $28.707 \mathrm{MPa}$ under 25 wt. $\%$ cellulose loading, $165^{\circ} \mathrm{C}$, and $15 \mathrm{~min}$ of mixing test conditions and the lowest impact strength value was $1.922 \mathrm{~kJ} / \mathrm{m}^{2}$ under $21.6 \mathrm{wt} . \%$ cellulose loading, $170^{\circ} \mathrm{C}$, and $20 \mathrm{~min}$ of mixing. When natural fibers are used as a reinforcing material in semicrystalline polymer matrices such as PLA, they can act as nucleating sites for crystal growth and commonly a transcrystalline layer grows from the crystalline cellulose surface [28, 42-44], which influences the mechanical properties of the composite. The statistical comparative study on tensile strength and impact strength of these composites was examined using RSM and the effects of the independent variables to the responses are discussed in the next section.

3.3. Model Selection and Verification of Tensile Strength and Impact Strength. The collected data was analyzed using software Design Expert 9. All the responses were analyzed using analysis of variance (ANOVA) and regression analysis for model fitting to evaluate the significance of the coefficient terms. The results are tabulated in Tables 4 through 6. The analysis of variance (ANOVA) for the quadratic model of tensile strength and impact strength are presented in Tables 4 and 5, respectively. The ANOVA demonstrated that the quadratic regression model of tensile strength was highly significant as the $F$-test had a very low probability value $(p<0.0001)$. This probability value means that there was only $0.01 \%$ chance that a "Model $F$ value" of this magnitude could occur due to noise [45]. The model of impact strength was $0.0006(p<0.05)$ which also indicated that the model was significant; however, the lack of fit $F$ value of 13.41 for tensile strength and 9.49 for impact strength implied that the lack of fits was also significant. The model, therefore, required further analysis. The goodness-of-fit of the models was further inspected using the $R^{2}$ value. The results showed that $R^{2}$ of the model for tensile strength and impact strength were 0.9621 and 0.9012 , respectively. In addition, the adequate precision values for both tensile strength and impact strength were well above 4; therefore, all the response surface models 
TABLE 4: Analysis of variance for the quadratic model of tensile strength.

\begin{tabular}{lccccc}
\hline Source & Sum of squares & DF & Mean squares & $F$ value & 28.18 \\
\hline Model & 715.11 & 9 & 79.46 & 2.82 & 13.41 \\
Residual & 28.20 & 10 & 5 & 5.25 & 0.0064 significant \\
Lack-of-fit & 26.24 & 5 & 0.39 & \\
Pure error & 1.96 & 19 & & \\
Total & 743.31 & & & \\
\hline
\end{tabular}

Std. dev. $=1.68$, mean $=35.92, R$-square $=0.9621$, and adeq. precision $=15.814$.

TABLE 5: Analysis of variance for the quadratic model of impact strength.

\begin{tabular}{lccccc}
\hline Source & Sum of squares & DF & Mean squares & $F$ value & 10.13 \\
\hline Model & 1.84 & 9 & 0.20 & 0.0006 significant \\
Residual & 0.20 & 10 & 0.020 & 9.49 & 0.0137 significant \\
Lack-of-fit & 0.18 & 5 & 0.037 & \\
Pure error & 0.019 & 5 & $3.850 E-003$ & \\
Total & 2.04 & 19 & & \\
\hline
\end{tabular}

Std. dev. $=0.14$, mean $=2.27, R$-square $=0.9012$, adeq. precision $=9.415$.

TABLE 6: Regression coefficients and probability values of approximate polynomials for response variables in experimental design.

\begin{tabular}{lcccc}
\hline \multirow{2}{*}{ Term } & \multicolumn{2}{c}{ Tensile strength } & \multicolumn{2}{c}{ Impact strength } \\
& Coefficient & Probability & Coefficient & Probability \\
\hline Constant & 30.45 & - & 2.01 & - \\
$X_{1}$ : cellulose & 3.74 & $<0.0001$ & 0.22 & 0.0002 \\
$X_{2}$ : temperature & -2.93 & $<0.0001$ & -0.14 & 0.0041 \\
$X_{3}$ : time & -2.10 & 0.0009 & -0.11 & 0.0148 \\
$X_{1}{ }^{2}$ & 3.79 & $<0.0001$ & 0.15 & 0.0029 \\
$X_{2}{ }^{2}$ & 2.55 & 0.0002 & 0.12 & 0.0103 \\
$X_{3}{ }^{2}$ & 1.68 & 0.0036 & 0.12 & 0.0076 \\
$X_{1} X_{2}$ & -1.63 & 0.0209 & -0.12 & 0.0382 \\
$X_{1} X_{3}$ & 1.83 & 0.0116 & 0.029 & 0.5752 \\
$X_{2} X_{3}$ & -0.82 & 0.1975 & -0.031 & 0.5538 \\
\hline
\end{tabular}

had the satisfactory values. From the above analysis, it can be concluded that these models are suitable for predicting the mechanical properties-tensile strength and impact strength of cellulose from durian rind-reinforced PLA composites within the limits of the experiment.

The $p$ values for each response are summarized in Table 6 . It was found that the terms in the model had a significant effect on the responses. For the tensile strength of the composites, the mixing temperature and mixing time interaction $\left(X_{2} X_{3}\right)$ was not significant, while the other model terms were concluded to be significant. For impact strength of the composites, the cellulose loading $\left(X_{1}\right)$, mixing temperature $\left(X_{2}\right)$, mixing time $\left(X_{3}\right)$, two-level interaction of cellulose loading $\left(X_{1}^{2}\right)$, mixing temperature $\left(X_{2}^{2}\right)$, mixing time $\left(X_{3}^{2}\right)$, and interaction of cellulose loading and mixing temperature $\left(X_{1} X_{2}\right)$ were all significant $(p<0.05)$. The other model terms were determined to not be significant. A higher value of regression coefficients can be directly translated to a greater effect of the independent variables on the responses [46].
Cellulose loading showed the highest regression coefficient value for both tensile strength and impact strength; therefore, it can be said that cellulose loading, compared to the other variables, had the greatest effect on tensile strength and impact strength. Moreover, the positive coefficients for the independent variables indicated a favorable effect on the mechanical properties [47]. The negative coefficients among the three independent variables indicated a partitioning favorable effect on the mechanical properties. Table 6 shows that only the main effect of cellulose loading represented favorable results on tensile strength and impact strength. The results demonstrated that the composites were best fit by the quadratic regression model for tensile strength and impact strength. The estimated models built for the tensile strength and impact strength methods are represented by (2) and (3) in terms of the coded values. It should be noted, however, that the following equations are only valid within the range of tested conditions: $15 \mathrm{wt} . \%<$ cellulose loading $<35 \mathrm{wt} . \%$, $165^{\circ} \mathrm{C}<$ mixing temperature $<175^{\circ} \mathrm{C}$, and $15 \mathrm{~min}<\operatorname{mixing}$ time $<25 \mathrm{~min}$.

For tensile strength, the model equation is as follows:

$$
\begin{aligned}
Y= & 30.45-3.74 X_{1}-2.93 X_{2}-2.10 X_{3}+3.79 X_{1}{ }^{2} \\
& +2.55 X_{2}{ }^{2}+1.68 X_{3}{ }^{2}-1.63 X_{1} X_{2}+1.83 X_{1} X_{3} \\
& -0.82 X_{2} X_{3} .
\end{aligned}
$$

For impact strength, the model equation is as follows:

$$
\begin{aligned}
Y= & 2.01+0.22 X_{1}-0.14 X_{2}-0.11 X_{3}+0.15 X_{1}^{2} \\
& +0.12 X_{2}^{2}+0.12 X_{3}^{2}-0.12 X_{1} X_{2}+0.029 X_{1} X_{3} \\
& -0.031 X_{2} X_{3},
\end{aligned}
$$

where $Y$ is the predicted response; $X_{1}$ is cellulose loading; $X_{2}$ is mixing temperature; and $X_{3}$ is mixing time.

A graphical representation of the models' quality is shown in Figure 3. The predicted $(Y)$ versus experimental $(X)$ 


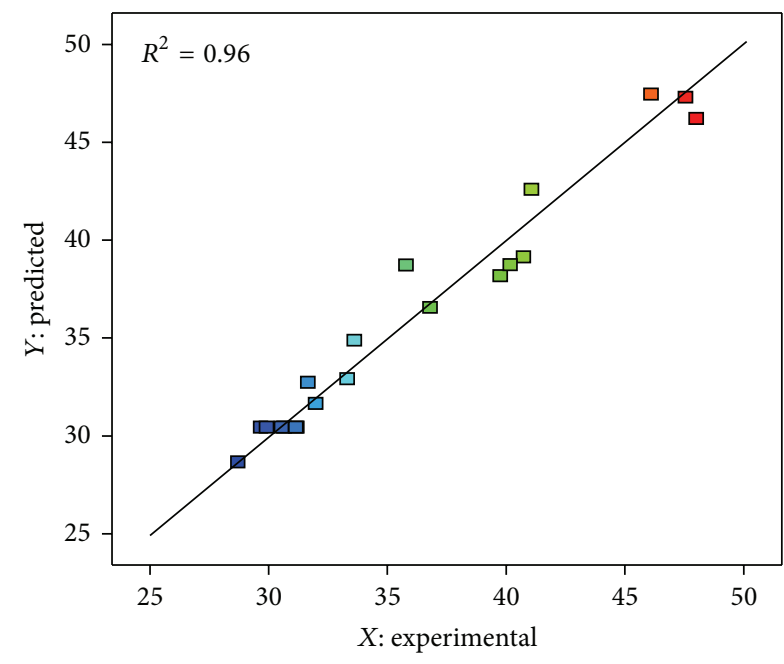

(a)

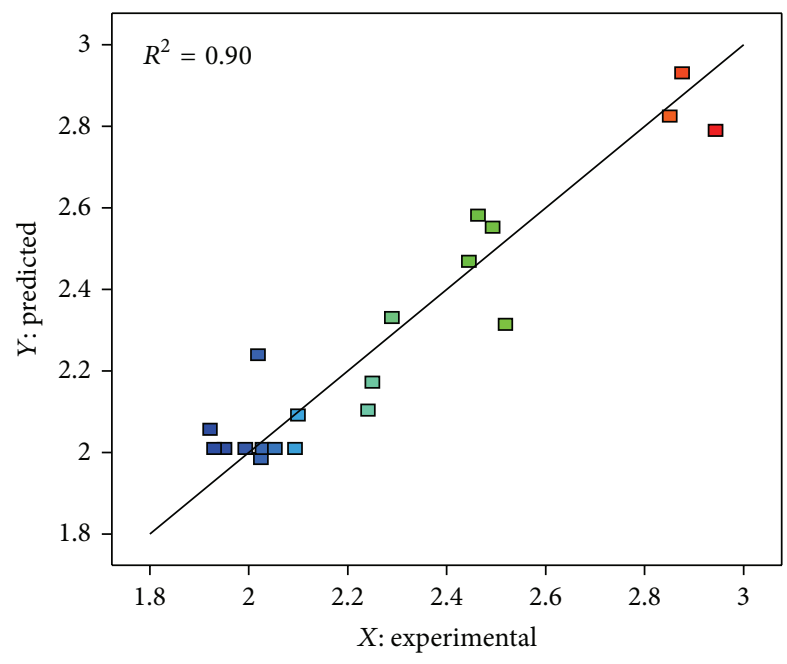

(b)

FIGURE 3: Correlation of predicted response versus experimental response: (a) tensile strength and (b) impact strength.

values for tensile strength (Figure 3(a)) and impact strength (Figure 3(b)) show that the quadratic model fits are suitable, with $R^{2}$ values for tensile strength and impact strength of 0.9612 and 0.9012 , respectively. These $R^{2}$ values indicate that only $3.79 \%$ of the tensile strength variation and $9.88 \%$ of the impact strength variation were not explained by the models.

3.4. Analysis of Response Surfaces. The 3D response surface plots and contour plots of the combined effects of the independent variables of cellulose loading, mixing temperature, and mixing time on tensile strength and impact strength are shown in Figures 4 and 5, according to (2) and (3), respectively. In this study, 3D response surfaces were obtained by keeping one of the variables constant at a zero level while varying the other two variables. It is observed from Figure 4 that there was a quadratic effect of cellulose loading, mixing temperature, and mixing time on tensile strength.

Figures 4(a) and 4(b) demonstrate that the cellulose loading had the most significant effect on the tensile strength, followed by mixing temperature and mixing time. The tensile strength increased with increase in cellulose loading. This result was similar to the findings of Tawakkal et al. [27]. They studied the effect of kenaf derived cellulose (KDC) loading on tensile properties and reported that both the tensile strength and tensile modulus were improved with increasing $\mathrm{KDC}$; the addition of KDC loading from 30 to $60 \mathrm{wt} . \%$ enhanced the strength of composites. In contrast, Sawpan et al. [29] investigated the mechanical properties of hemp fiber-reinforced (range 0 to $40 \mathrm{wt}$.\%) PLA biocomposites and found that the relationship between tensile strength and fiber content was not linear. This indicated that at a higher fiber content, the addition somewhat decreased the strength of the composite.

Figure 4(c) illustrates that tensile strength slightly decreased with an increase in mixing temperature at a constant cellulose loading of $30 \mathrm{wt} . \%$. As shown in Table 2, the highest tensile strength was obtained when the cellulose loading was at its highest level, lowest mixing temperature, and lowest mixing time within the ranges tested. The decrease in tensile strength at the higher mixing temperature and longer mixing time can be due to the thermal degradation of cellulose [48]. It is known that fiber shortening inevitably occurs during mixing of composites with both natural fiber $[49,50]$ and synthetic fiber [51], related to the strong shear stress endured by the viscous molten polymer [29]. As the fiber content increased, the possibility of this phenomena occurring during mixing with interaction between the fiber and equipment wall increased, resulting in fibers shorter than the critical length and reduced aspect ratio, which directly affected the performance of the composites [48] and decreased the tensile strength. Generally, the aspect ratio has to be superior to 10 , which is considered to be the minimum aspect ratio for good strength transmission for any reinforcement [41]. In addition, Kannappan and Dhurai [5] reported that time did not make a significant difference in tensile strength; hence, an increase in temperature increased the tensile strength. Melting occurs when the polymer chains fall out of their crystal structures and become a disorder liquid to cause good binding results between the reinforcement fibers, which in turn increase the tensile strength.

Figures 5(a) and 5(b) present that cellulose loading had the most significant effect on the impact strength. It is clear that when cellulose loading increased, impact strength also increased rapidly at a minimum temperature as shown in Figure 5(a). According to Bledzki and Jaszkiewicz [25], the massive increase in impact performance for all man-made cellulose composites is due to smaller diameter and smoother surface, which affects the fiber/matrix interaction and, therefore, allowing for pullout to occur. The cellulose used in this study was extracted using a chlorination method to remove lignin followed by mercerization to convert holocellulose to alpha cellulose. After these two steps the noncellulosic components scattered over the surface were removed and resulted in a decreased diameter and smoother surface. 


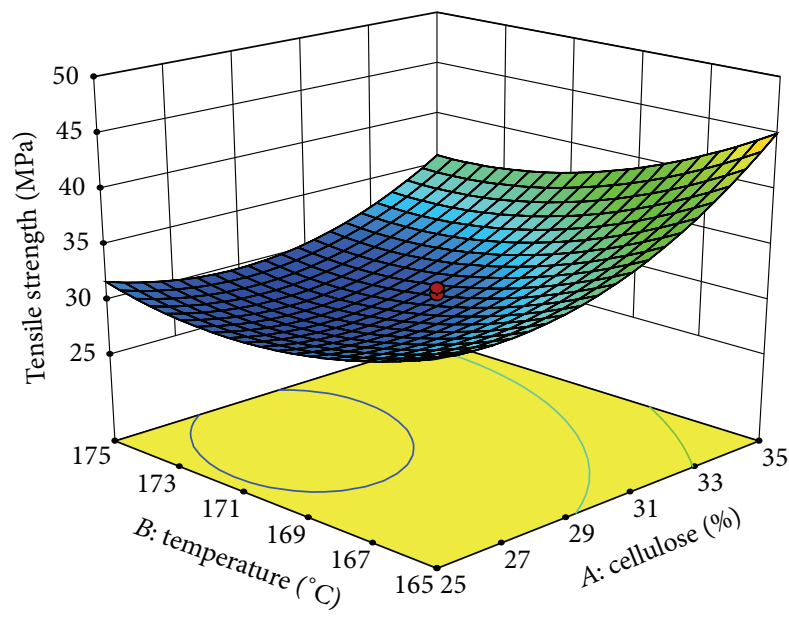

(a)

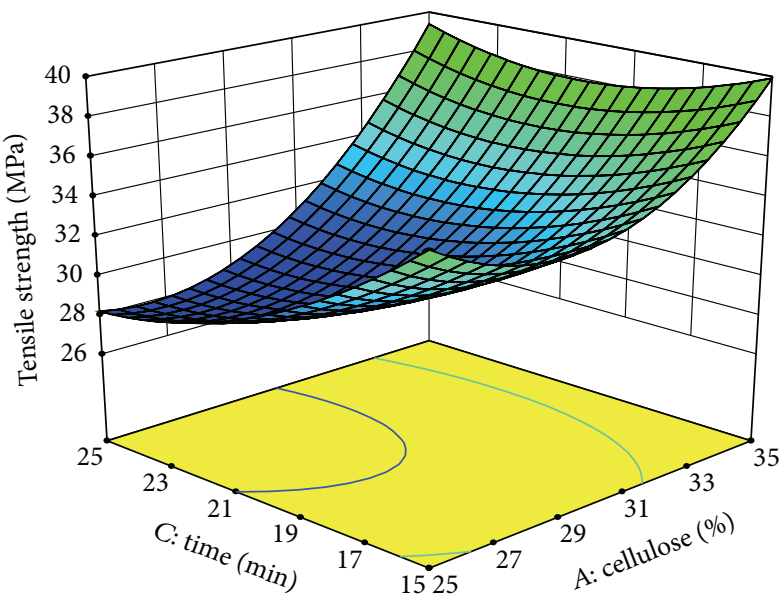

(b)

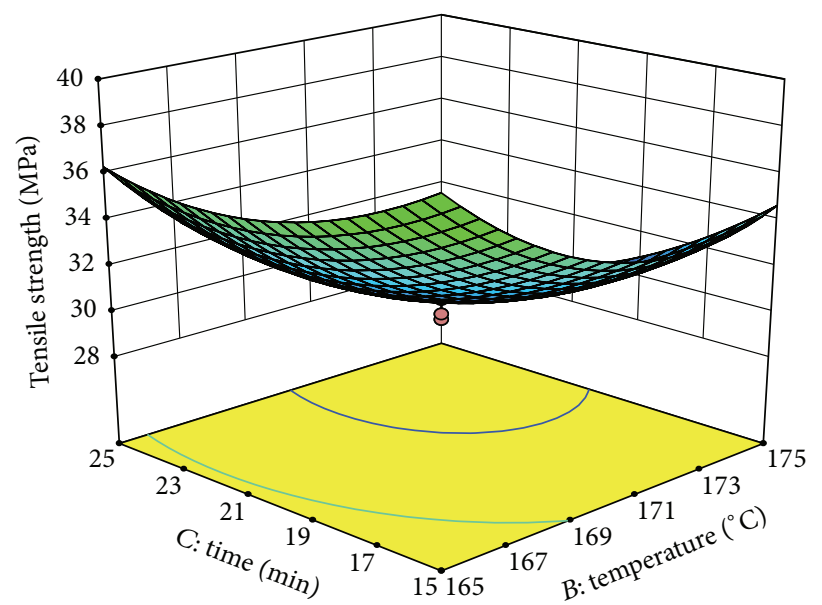

(c)

FIGURE 4: Response surfaces plots of the combined effects of the independent variables on tensile strength of biocomposites.

Supposedly, for this reason, the path length of the propagated crack is enlarged, increasing the amount of energy needed to break the sample [52]. Figure 5(c) indicates that at a minimum mixing temperature, impact strength increased with increased mixing time, whereas at a high temperature, the longer time caused a decrease in impact strength. Tawakkal et al. [30] reported that adding kenaf derived cellulose (KDC) to the PLA matrix did not significantly contribute to the total impact strength of the composites; however, it was found that a 30 wt.\% KDC/PLA composite achieved the highest impact strength, with a slightly reduced strength with the addition of 40 to 60 wt. $\%$ KDC. The decrease in impact strength indicates the lesser capacity to absorb energy under impact, due to higher crack propagation and crack initiation [53].

3.5. Optimization of the Experiments. Response surface methodology (RSM) was used to optimize the conditions for the preparation of composites. The design of experiment was carried out using Design Expert 9. In the optimization selection, there were three factors for a goal to construct desirability indices: cellulose loading, mixing temperature, and mixing time. After optimization, there were some solutions for the mechanical properties of the composites as shown in Table 6. The goal for both tensile strength and impact strength was to maximize the strengths; therefore, the target value of the responses was the highest values from the experimental results obtained. The optimization of the responses of tensile strength and impact strength is displayed in Figure 6. The acceptable values of the desirability function were the values close to one (100\%). In this study, the mechanical properties of the biocomposite compromised with 35 wt. $\%$ cellulose loading, $165^{\circ} \mathrm{C}$ mixing temperature, and 15 min of mixing time had $94.6 \%$ desirability. These levels of the independent variables yield the highest responses of tensile strength and impact strength: $46.207 \mathrm{MPa}$ and $2.931 \mathrm{~kJ} / \mathrm{m}^{2}$, respectively.

This study found that the addition of cellulose, however, caused a decreasing tensile strength when compared to the neat PLA (prepared at center point with $170^{\circ} \mathrm{C}$ and $20 \mathrm{~min}$ of mixing), which produced a strength of $52.422 \mathrm{MPa}$ (data not shown). Yang et al. [54] reported that an irregular shape of the reinforcement materials causes the strength 


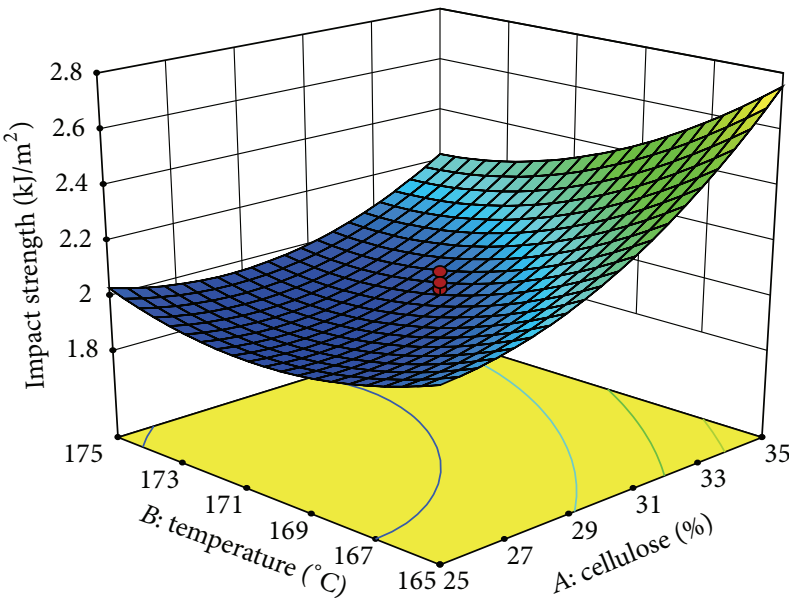

(a)

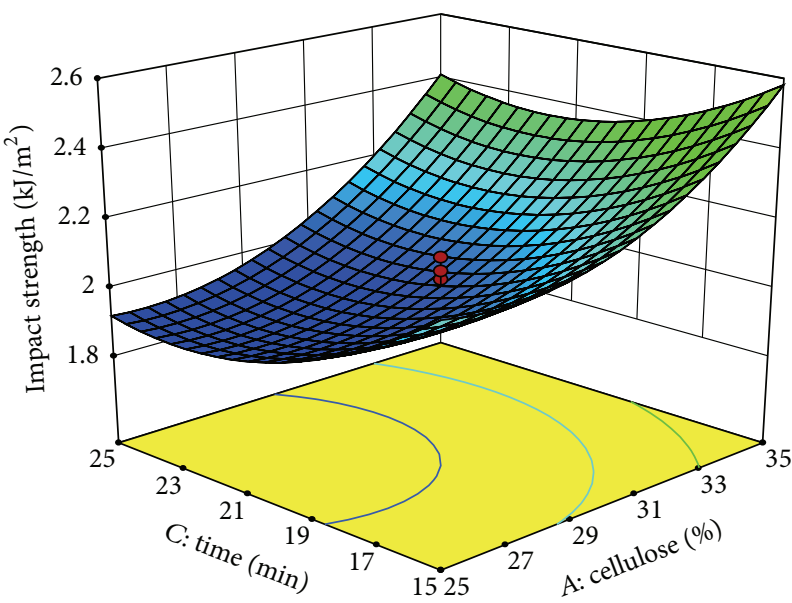

(b)

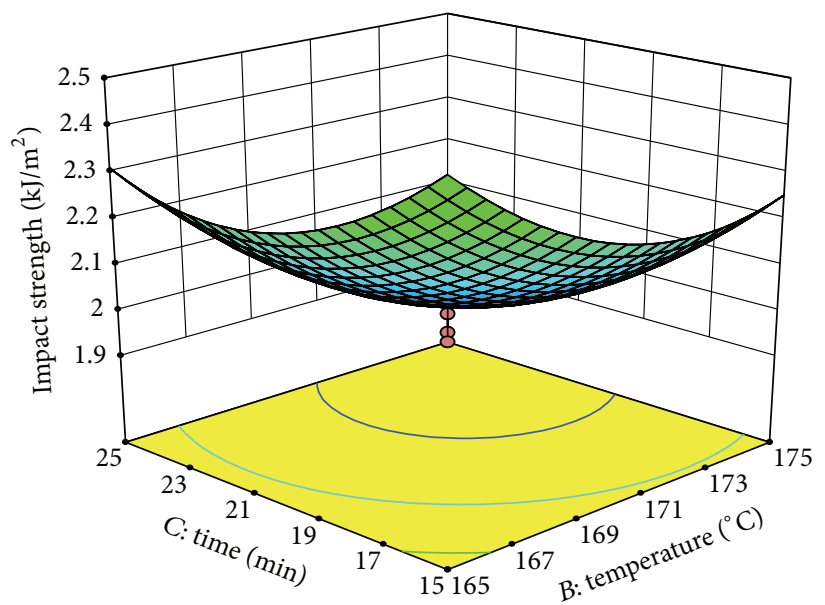

(c)

FIGURE 5: Response surface plots of the combined effects of the independent variables on impact strength of biocomposites.
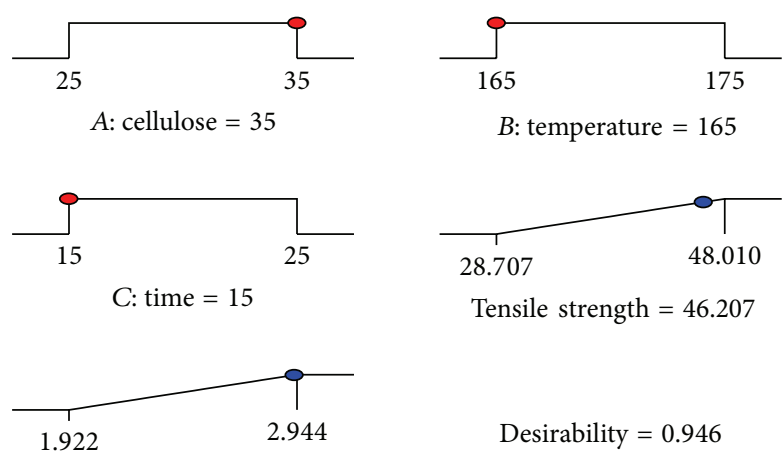

Impact strength $=2.931$

FIGURE 6: Optimum condition of the independent variables and the responses of the biocomposites.

of the composites to decrease due to the inability of the reinforcement to support stress transfer from the polymer matrix. A weak interfacial region will reduce the efficiency of the stress transfer from the matrix to the reinforcing component, lowering its strength [55]. The result was similar to Wang et al. [33], where they found that the strength of composites decreased with increasing amount of rice hull. A major limitation of using plant fiber and cellulose for reinforcement is that adhesion between the two materials is expected to be rather poor because of the polar nature of fiber and the nonpolar groups of thermoplastics such as poly(lactic acid) [56-58]. The quality of interfacial bonding is determined by several factors, such as the nature of the fiber and polymer components, the fiber aspect ratio, the processing procedure, and the treatment of the polymer or fiber [59-62]. To obtain materials with improved mechanical properties, the efficient dispersion of one phase into the other is required.

3.6. Spectroscopy Analysis. The structure of polymer composites can be identified using FTIR. If two components form completely immiscible blend, then there should be no considerable changes in the IR spectra of composites compared 


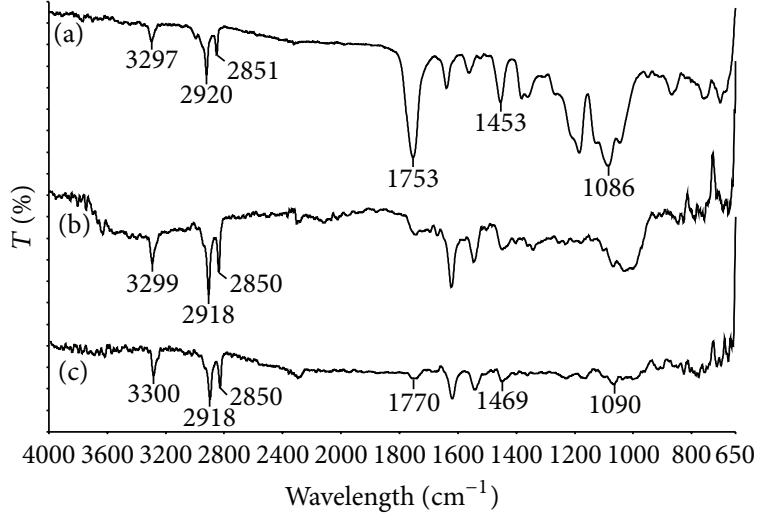

FIGURE 7: FTIR spectra for (a) poly(lactic acid), (b) cellulose, and (c) biocomposites.

with each component spectra [63]. However, if two polymers are compatible, a distinct chemical interaction (hydrogenbonding or dipolar interaction) exists between the chains of polymer and those of additional component, affecting the IR spectra of composites to change (e.g., band shifting and broadening) [64]. Figure 7 shows the spectra of PLA, cellulose and biocomposites (PLA/cellulose blends). Peaks near 3400$3200 \mathrm{~cm}^{-1}$ and $3000-2850 \mathrm{~cm}^{-1}$ were observed in all spectra which are attributed to $\mathrm{O}-\mathrm{H}$ stretching group [37] and C$\mathrm{H}$ stretching [65], respectively. For neat PLA, the strong absorption peak at $1753 \mathrm{~cm}^{-1}$ is assigned to stretching of $\mathrm{C}=\mathrm{O}$ group [27, 63, 66] and peak at 1080 and $1453 \mathrm{~cm}^{-1}$ represents $\mathrm{C}-\mathrm{O}$ group of ester bonds and asymmetrical stretching of $-\mathrm{CH}_{3}$ group [66]. It was seen that there were shifts of $\mathrm{C}=\mathrm{O}$ peak at $1753 \mathrm{~cm}^{-1}$ and C-O peak at $1086 \mathrm{~cm}^{-1}$ (neat PLA) to peak at $1770 \mathrm{~cm}^{-1}$ and $1090 \mathrm{~cm}^{-1}$ in biocomposites. These shifts might be because of the formation of hydrogen bonding between $-\mathrm{OH}$ in cellulose and $\mathrm{C}=\mathrm{O}$ and $\mathrm{C}-\mathrm{O}$ in PLA [27, 30, 67]. The peak at $1453 \mathrm{~cm}^{-1}$ (neat PLA) moved toward higher wavenumber of $1469 \mathrm{~cm}^{-1}$ in biocomposites. The observations further indicated the presence of interactions between the PLA matrix and cellulose surfaces.

\section{Conclusion}

The biocomposites showed that tensile strength ranged from 28.707 to $48.010 \mathrm{MPa}$ and impact strength ranged from 1.922 to $2.944 \mathrm{~kJ} / \mathrm{m}^{2}$. The highest tensile strength value was $48.010 \mathrm{MPa}$ with conditions of $35 \mathrm{wt} . \%$ cellulose loading, $165^{\circ} \mathrm{C}$, and $15 \mathrm{~min}$ of mixing, while the highest impact strength value was $2.944 \mathrm{~kJ} / \mathrm{m}^{2}$ under $38.4 \mathrm{wt} \%$ cellulose, $170^{\circ} \mathrm{C}$, and $20 \mathrm{~min}$ of mixing. The quadratic regression model was selected for modeling the tensile strength and impact strength due to its high significance level. The $R^{2}$ values of the model for tensile strength and impact strength were 0.9621 and 0.9012 , respectively. Both tensile strength and impact strength had adequate precision values above 4; thus, these models can be used to predict the mechanical properties of biocomposites composed of poly(lactic acid) and cellulose from durian rind. Cellulose loading, mixing temperature, and mixing time were significant variables in affecting tensile strength and impact strength. The order of independent variables according to the significance was cellulose loading followed by mixing temperature and mixing time. The optimal conditions considering the mechanical properties was found to be at cellulose loading, mixing temperature, and mixing time of $35 \mathrm{wt} . \%, 165^{\circ} \mathrm{C}$, and $15 \mathrm{~min}$ with a desirability of $94.16 \%$. At this optimal condition, the tensile strength and impact strength were found to be $46.207 \mathrm{MPa}$ and $2.931 \mathrm{~kJ} / \mathrm{m}^{2}$, respectively.

\section{Conflict of Interests}

The authors declare that there is no conflict of interests regarding the publication of this paper.

\section{Acknowledgments}

The authors would like to thank the German Academic Exchange Service (DAAD) and Southeast Asian Regional Center for Graduate Study and Research in Agriculture (SEARCA) for their financial support. All the technical staff in Department of Process and Food Engineering, Faculty of Engineering and Institute of Tropical Forestry and Forest Products, Universiti Putra Malaysia, are greatly acknowledged for their assistance.

\section{References}

[1] A. T. Seadi and J. B. Holm-Nielsen, "Utilization of waste from food and agriculture," in Solid Waste: Assesment, Monitoring and Remediation, J. Twardowskai, H. E. Allen, A. F. Kettrup, and W. J. Lacy, Eds., Elsevier B.V., Philadelphia, Pa, USA, 2004.

[2] E. Schettini, G. Santagata, M. Malinconico, B. Immirzi, G. S. Mugnozza, and G. Vox, "Recycled wastes of tomato and hemp fibres for biodegradable pots: physico-chemical characterization and field performance," Resources, Conservation and Recycling, vol. 70, pp. 9-19, 2013.

[3] F. Federici, F. Fava, N. Kalogerakis, and D. Mantzavinos, "Valorisation of agro-industrial by-products, effluents and waste: concept, opportunities and the case of olive mill wastewaters," Journal of Chemical Technology and Biotechnology, vol. 84, no. 6, pp. 895-900, 2009.

[4] S. Ochi, "Mechanical properties of kenaf fibers and kenaf/PLA composites," Mechanics of Materials, vol. 40, no. 4-5, pp. 446452, 2008.

[5] S. Kannappan and B. Dhurai, "Investigating and optimizing the process variables related to the tensile properties of short jute fiber reinforced with polypropylene composite board," Journal of Engineered Fibers and Fabrics, vol. 7, no. 4, pp. 28-34, 2012.

[6] N. Cañigueral, F. Vilaseca, J. A. Méndez et al., "Behavior of biocomposite materials from flax strands and starch-based biopolymer," Chemical Engineering Science, vol. 64, no. 11, pp. 2651-2658, 2009.

[7] K. Okubo, T. Fujii, and E. T. Thostenson, "Multi-scale hybrid biocomposite: processing and mechanical characterization of bamboo fiber reinforced PLA with microfibrillated cellulose," Composites Part A: Applied Science and Manufacturing, vol. 40, no. 4, pp. 469-475, 2009. 
[8] T. Yu, J. Ren, S. Li, H. Yuan, and Y. Li, "Effect of fiber surfacetreatments on the properties of poly(lactic acid)/ramie composites," Composites Part A: Applied Science and Manufacturing, vol. 41, no. 4, pp. 499-505, 2010.

[9] M. Li, L.-J. Wang, D. Li, Y.-L. Cheng, and B. Adhikari, "Preparation and characterization of cellulose nanofibers from depectinated sugar beet pulp," Carbohydrate Polymers, vol. 102, no. 1, pp. 136-143, 2014.

[10] N. Johar, I. Ahmad, and A. Dufresne, "Extraction, preparation and characterization of cellulose fibres and nanocrystals from rice husk," Industrial Crops and Products, vol. 37, no. 1, pp. 9399, 2012.

[11] L. Avérous and F. Le Digabel, "Properties of biocomposites based on lignocellulosic fillers," Carbohydrate Polymers, vol. 66, no. 4, pp. 480-493, 2006.

[12] R. M. N. Arib, S. M. Sapuan, M. M. H. M. Ahmad, M. T. Paridah, and H. M. D. Khairul Zaman, "Mechanical properties of pineapple leaf fibre reinforced polypropylene composites," Materials and Design, vol. 27, no. 5, pp. 391-396, 2006.

[13] A. K. Bledzki, A. A. Mamun, and J. Volk, "Barley husk and coconut shell reinforced polypropylene composites: the effect of fibre physical, chemical and surface properties," Composites Science and Technology, vol. 70, no. 5, pp. 840-846, 2010.

[14] A. Nourbakhsh, F. F. Baghlani, and A. Ashori, "Nano-SiO filled rice husk/polypropylene composites: physico-mechanical properties," Industrial Crops and Products, vol. 33, no. 1, pp. 183187, 2011.

[15] J. O. Agunsoye and V. S. Aigbodion, "Bagasse filled recycled polyethylene bio-composites: morphological and mechanical properties study," Results in Physics, vol. 3, pp. 187-194, 2013.

[16] A. Dufresne, "Comparing the mechanical properties of high performance polymer nanocomposites from biological sources," Journal of Nanoscience and Nanotechnology, vol. 6, no. 2, pp. 322-330, 2006.

[17] J. X. Sun, X. F. Sun, H. Zhao, and R. C. Sun, "Isolation and characterization of cellulose from sugarcane bagasse," Polymer Degradation and Stability, vol. 84, no. 2, pp. 331-339, 2004.

[18] A. Mandal and D. Chakrabarty, "Isolation of nanocellulose from waste sugarcane bagasse (SCB) and its characterization," Carbohydrate Polymers, vol. 86, no. 3, pp. 1291-1299, 2011.

[19] K. Goda, M. S. Sreekala, A. Gomes, T. Kaji, and J. Ohgi, "Improvement of plant based natural fibers for toughening green composites-effect of load application during mercerization of ramie fibers," Composites Part A: Applied Science and Manufacturing, vol. 37, no. 12, pp. 2213-2220, 2006.

[20] A. K. Bledzki and J. Gassan, "Composites reinforced with cellulose based fibres," Progress in Polymer Science, vol. 24, no. 2, pp. 221-274, 1999.

[21] A. N. Frone, S. Berlioz, J.-F. Chailan, D. M. Panaitescu, and D. Donescu, "Cellulose fiber-reinforced polylactic acid," Polymer Composites, vol. 32, no. 6, pp. 976-985, 2011.

[22] B. Tajeddin, R. A. Rahman, L. C. Abdulah, Y. A. Yusof, and N. A. Ibrahim, "Effect of PEG on the biodegradability studies of Kenaf cellulose -polyethylene composites," International Food Research Journal, vol. 16, pp. 243-247, 2009.

[23] L. Suryanegara, A. N. Nakagaito, and H. Yano, "The effect of crystallization of PLA on the thermal and mechanical properties of microfibrillated cellulose-reinforced PLA composites," Composites Science and Technology, vol. 69, no. 7-8, pp. 11871192, 2009.
[24] J. Ahmed, S. K. Varshney, and R. Auras, "Rheological and thermal properties of polylactide/silicate nanocomposites films," Journal of Food Science, vol. 75, no. 2, pp. N17-N24, 2010.

[25] A. K. Bledzki and A. Jaszkiewicz, "Mechanical performance of biocomposites based on PLA and PHBV reinforced with natural fibres-a comparative study to PP," Composites Science and Technology, vol. 70, no. 12, pp. 1687-1696, 2010.

[26] P. Qu, Y. Gao, G.-F. Wu, and L.-P. Zhang, "Nanocomposites of poly(lactic acid) reinforced with cellulose nanofibrils," BioResources, vol. 5, no. 3, pp. 1811-1823, 2010.

[27] I. S. M. A. Tawakkal, R. A. Talib, K. Abdan, and N. L. Chin, "Optimisation of processing variables of kenaf derived cellulose reinforced polylactic acid," Asian Journal of Chemistry, vol. 22, no. 9, pp. 6652-6662, 2010.

[28] K. L. Pickering, M. A. Sawpan, J. Jayaraman, and A. Fernyhough, "Influence of loading rate, alkali fibre treatment and crystallinity on fracture toughness of random short hemp fibre reinforced polylactide bio-composites," Composites Part A: Applied Science and Manufacturing, vol. 42, no. 9, pp. 1148-1156, 2011.

[29] M. A. Sawpan, K. L. Pickering, and A. Fernyhough, "Improvement of mechanical performance of industrial hemp fibre reinforced polylactide biocomposites," Composites Part A: Applied Science and Manufacturing, vol. 42, no. 3, pp. 310-319, 2011.

[30] I. S. M. A. Tawakkal, R. A. Talib, K. Abdan, and C. N. Ling, "Mechanical and physical properties of kenaf-derived cellulose (KDC)-filled polylactic acid (PLA) composites," BioResources, vol. 7, no. 2, pp. 1643-1655, 2012.

[31] K. Halász and L. Csóka, "Plasticized biodegradable poly(lactic acid) based composites containing cellulose in micro- and nano size," Journal of Engineering, vol. 2013, Article ID 329379, 9 pages, 2013.

[32] A. Jiang, X. Xu, and H. Wu, "Preparation and properties of Llactide grafted sisal fiber reinforced poly(lactic acid) composites," Polymer Composites, 2014.

[33] X. Wang, H. Sun, H. Bai, and L.-P. Zhang, “Thermal, mechanical, and degradation properties of nanocomposites prepared using lignin-cellulose nanofibers and poly (lactic acid)," BioResources, vol. 9, no. 2, pp. 3211-3244, 2014.

[34] B. T. Amid and H. Mirhosseini, "Optimisation of aqueous extraction of gum from durian (Durio zibethinus) seed: a potential, low cost source of hydrocolloid," Food Chemistry, vol. 132, no. 3, pp. 1258-1268, 2012.

[35] K. Y. Foo and B. H. Hameed, "Transformation of durian biomass into a highly valuable end commodity: trends and opportunities," Biomass and Bioenergy, vol. 35, no. 7, pp. 24702478, 2011.

[36] P. Rachtanapun, S. Luangkamin, K. Tanprasert, and R. Suriyatem, "Carboxymethyl cellulose film from durian rind," $L W T-$ Food Science and Technology, vol. 48, no. 1, pp. 52-58, 2012.

[37] P. Penjumras, R. B. Rahman, R. A. Talib, and K. Abdan, "Extraction and characterization of cellulose from durian rind," Agriculture and Agricultural Science Procedia, vol. 2, pp. 237243, 2014.

[38] J. S. Han and J. S. Rowell, "Chemical composition of fibers," in Paper and Composites from Agro-Based Resources, R. M. Rowell and J. Rowell, Eds., pp. 83-130, CRC Press, London, UK, 1996.

[39] ASTM, "Standard test methods for tensile-impact energy to break plastics and electrical insulating materials," ASTM D 1882L, ASTM International, West Conshohocken, Pa, USA, 2002. 
[40] ASTM International, "Standard test methods for determining the izod pendulum impact resistance of plastics," ASTM D 256, ASTM International, West Conshohocken, Pa, USA, 2004.

[41] A. Bourmaud and S. Pimbert, "Investigations on mechanical properties of poly(propylene) and poly(lactic acid) reinforced by miscanthus fibers," Composites Part A: Applied Science and Manufacturing, vol. 39, no. 9, pp. 1444-1454, 2008.

[42] A. P. Mathew, K. Oksman, and M. Sain, "The effect of morphology and chemical characteristics of cellulose reinforcements on the crystallinity of polylactic acid," Journal of Applied Polymer Science, vol. 101, no. 1, pp. 300-310, 2006.

[43] R. Masirek, Z. Kulinski, D. Chionna, E. Piorkowska, and M. Pracella, "Composites of poly(L-lactide) with hemp fibers: morphology and thermal and mechanical properties," Journal of Applied Polymer Science, vol. 105, no. 1, pp. 255-268, 2007.

[44] S. Pilla, S. Gong, E. O’Neill, R. M. Rowell, and A. M. Krzysik, "Polylactide-pine wood flour composites," Polymer Engineering and Science, vol. 48, no. 3, pp. 578-587, 2008.

[45] C. Lv, Y. Wang, L.-J. Wang, D. Li, and B. Adhikari, "Optimization of production yield and functional properties of pectin extracted from sugar beet pulp," Carbohydrate Polymers, vol. 95, no. 1, pp. 233-240, 2013.

[46] B. P. Chang, H. M. Akil, M. G. Affendy, A. Khan, and R. B. Nasir, "Comparative study of wear performance of particulate and fiber-reinforced nano- $\mathrm{ZnO} /$ ultra-high molecular weight polyethylene hybrid composites using response surface methodology," Materials \& Design, vol. 63, pp. 805-819, 2014.

[47] A. E. Hadi, Characterisation and optimisation of mechanical, physical and thermal properties of short Abaca (Musa Textile Nee) fibre reinforced high impact polystyrene composites [Ph.D. thesis], Universiti Putra Malaysia, 2011.

[48] P. V. Joseph, K. Joseph, and S. Thomas, "Effect of processing variables on the mechanical properties of sisal-fiber-reinforced polypropylene composites," Composites Science and Technology, vol. 59, no. 11, pp. 1625-1640, 1999.

[49] H. L. Bos, J. Müssig, and M. J. A. van den Oever, "Mechanical properties of short-flax-fibre reinforced compounds," Composites Part A: Applied Science and Manufacturing, vol. 37, no. 10, pp. 1591-1604, 2006.

[50] R. Tokoro, D. M. Vu, K. Okubo, T. Tanaka, T. Fujii, and T. Fujiura, "How to improve mechanical properties of polylactic acid with bamboo fibers," Journal of Materials Science, vol. 43, no. 2, pp. 775-787, 2008.

[51] S.-Y. Fu, B. Lauke, E. Mäder, C.-Y. Yue, and X. Hu, “Tensile properties of short-glass-fiber- and short-carbon-fiber-reinforced polypropylene composites," Composites Part A: Applied Science and Manufacturing, vol. 31, no. 10, pp. 1117-1125, 2000.

[52] A. K. Bledzki, A. Jaszkiewicz, and D. Scherzer, "Mechanical properties of PLA composites with man-made cellulose and abaca fibres," Composites Part A: Applied Science and Manufacturing, vol. 40, no. 4, pp. 404-412, 2009.

[53] M. S. Huda, L. T. Drzal, M. Misra, and A. K. Mohanty, "Woodfiber-reinforced poly(lactic acid) composites: evaluation of the physicomechanical and morphological properties," Journal of Applied Polymer Science, vol. 102, no. 5, pp. 4856-4869, 2006.

[54] H.-S. Yang, H.-J. Kim, J. Son, H.-J. Park, B.-J. Lee, and T.S. Hwang, "Rice-husk flour filled polypropylene composites; mechanical and morphological study," Composite Structures, vol. 63, no. 3-4, pp. 305-312, 2004.
[55] J. C. Miguez Suarez, F. M. B. Coutinho, and T. H. Sydenstricker, "SEM studies of tensile fracture surfaces of polypropylenesawdust composites," Polymer Testing, vol. 22, no. 7, pp. 819-824, 2003.

[56] M. Abdelmouleh, S. Boufi, M. N. Belgacem, and A. Dufresne, "Short natural-fibre reinforced polyethylene and natural rubber composites: effect of silane coupling agents and fibres loading," Composites Science and Technology, vol. 67, no. 7-8, pp. 16271639, 2007.

[57] J. Lu, P. Askeland, and L. T. Drzal, "Surface modification of microfibrillated cellulose for epoxy composite applications," Polymer, vol. 49, no. 5, pp. 1285-1296, 2008.

[58] Y. Xie, C. A. S. Hill, Z. Xiao, H. Militz, and C. Mai, "Silane coupling agents used for natural fiber/polymer composites: a review," Composites Part A: Applied Science and Manufacturing, vol. 41, no. 7, pp. 806-819, 2010.

[59] C.-H. Hsueh, "Interfacial debonding and fiber pull-out stresses of fiber-reinforced composites IV: sliding due to residual stresses," Materials Science and Engineering A, vol. 145, no. 2, pp. 143-150, 1991.

[60] J. M. Felix, P. Gatenholm, and H. P. Schreiber, "Controlled interactions in cellulose-polymer composites 1: effect on mechanical properties," Polymer Composites, vol. 14, no. 6, pp. 449-457, 1993.

[61] A. Valadez-Gonzalez, J. M. Cervantes-Uc, R. Olayo, and P. J. Herrera-Franco, "Effect of fiber surface treatment on the fibermatrix bond strength of natural fiber reinforced composites," Composites Part B: Engineering, vol. 30, no. 3, pp. 309-320, 1999.

[62] K. V. Pochiraju, G. P. Tandon, and N. J. Pagano, "Analyses of single fiber pushout considering interfacial friction and adhesion," Journal of the Mechanics and Physics of Solids, vol. 49, no. 10, pp. 2307-2338, 2001.

[63] G. Zhang, J. Zhang, X. Zhou, and D. Shen, "Miscibility and phase structure of binary blends of polylactide and poly(vinylpyrrolidone)," Journal of Applied Polymer Science, vol. 88, no. 4, pp. 973-979, 2003.

[64] S. Peng, X. Wang, and L. Dong, "Special interaction between poly (propylene carbonate) and corn starch," Polymer Composites, vol. 26, no. 1, pp. 37-41, 2005.

[65] B. W. Chieng, N. A. Ibrahim, Y. Y. Then, and Y. Y. Loo, "Epoxidized vegetable oils plasticized poly(lactic acid) biocomposites: mechanical, thermal and morphology properties," Molecules, vol. 19, no. 10, pp. 16024-16038, 2014.

[66] K. M. Z. Hossain, I. Ahmed, A. J. Parsons et al., "Physicochemical and mechanical properties of nanocomposites prepared using cellulose nanowhiskers and poly(lactic acid)," Journal of Materials Science, vol. 47, no. 6, pp. 2675-2686, 2012.

[67] D. Garlotta, W. Doane, R. Shogren, J. Lawton, and J. L. Willett, "Mechanical and thermal properties of starch-filled poly(D,Llactic acid)/poly(hydroxy ester ether) biodegradable blends," Journal of Applied Polymer Science, vol. 88, no. 7, pp. 1775-1786, 2003. 

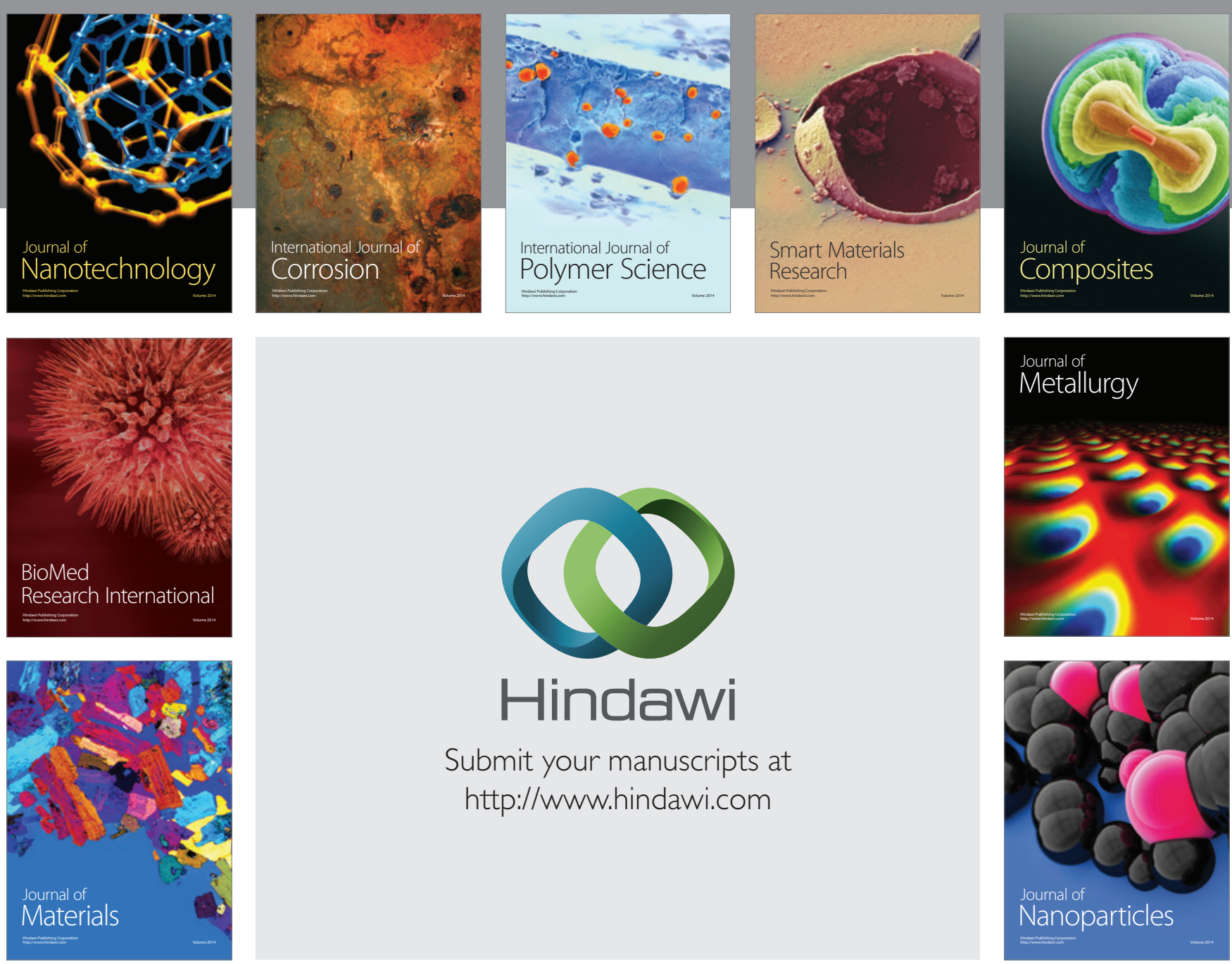

Submit your manuscripts at http://www.hindawi.com
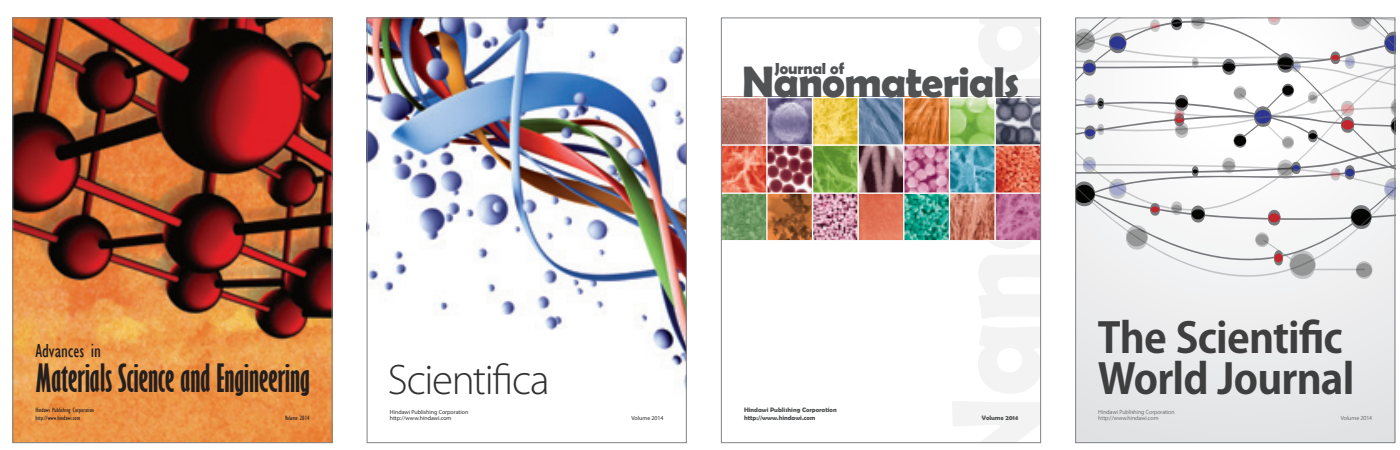

\section{The Scientific World Journal}
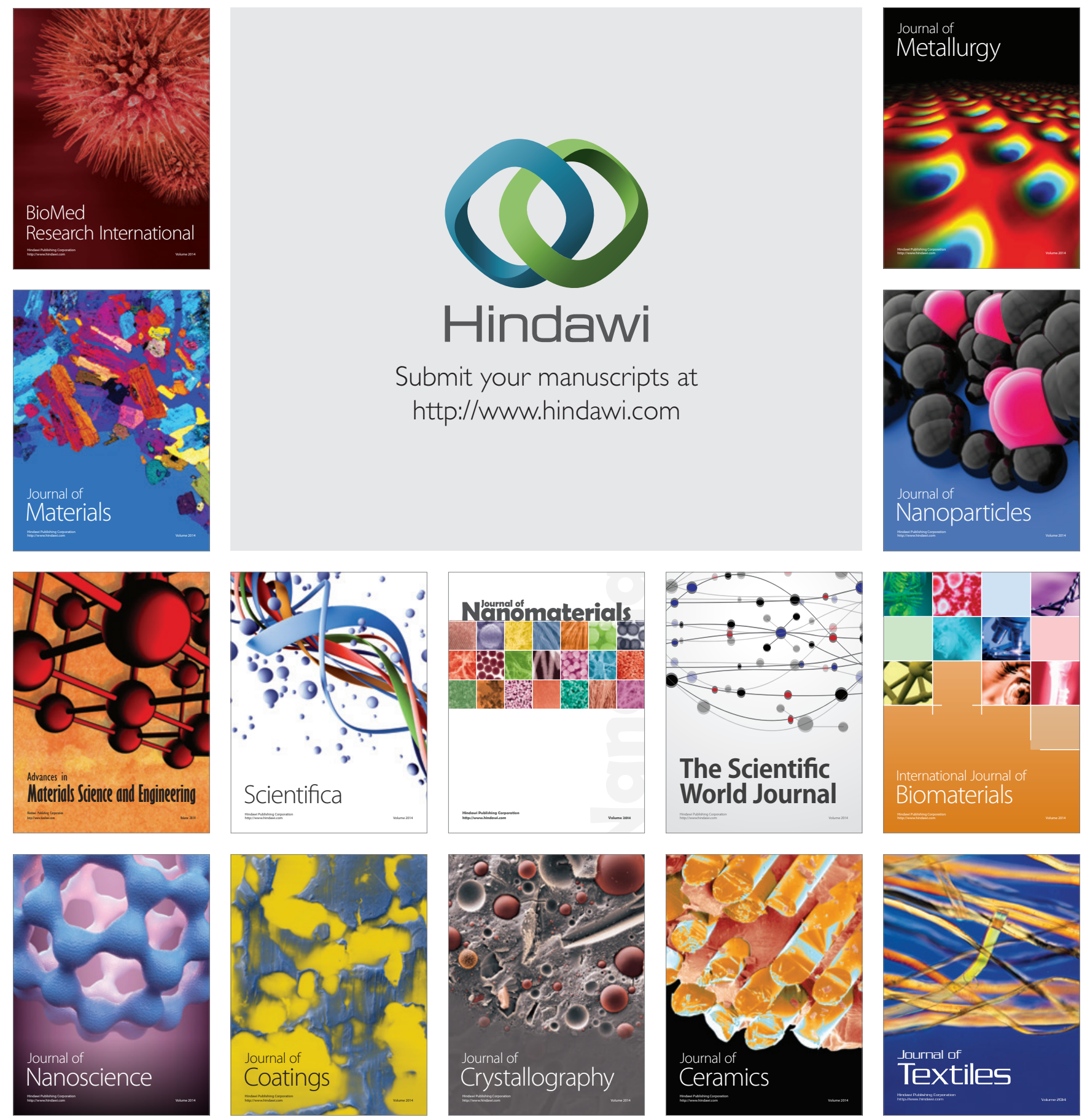